\title{
Assessment of apparent diffusion coefficient value as prognostic factor for renal cell carcinoma aggressiveness
}

\author{
Medhat Ibraheem Mohammad Ahmad ${ }^{1 *}$, Mohammad Sabr $^{2+}$ and Eman Roshy ${ }^{3+}$
}

\begin{abstract}
Background: Assurance of prognostic elements is important for the management of renal cell carcinoma (RCC). Our goal was to check the relation between apparent diffusion coefficient (ADC) values and parameters predicting prognosis of RCC. Fifty pathologically confirmed RCC underwent diffusion-weighted (DW) MRI. ADC values were calculated using $b$ factor $\left(800 \mathrm{~s} / \mathrm{mm}^{2}\right)$. The correlation between ADC values and tumor size, cystic/necrotic feature, growth pattern, unenhanced T1, histological grade, clinical stage, and distant metastasis were analyzed.

Results: The optimal ADC threshold for prognosis of RCC appeared to be $1.4 \times 10^{-3} \mathrm{~mm}^{2} / \mathrm{s}$. There was a significant inverse correlation between $\mathrm{ADC}$ values and growth pattern $(R=-0, P=0.05)$, unenhanced $\mathrm{T} 1(R=-0.41, P=0.01)$, cystic/necrotic feature $(R=-0.4, P=0.01)$, histological grade $(R=-0.37, P=0.02)$, clinical stage $(r=-0.4, P=0.01)$, and distant metastasis $(R=-0.33, P=0.04)$, and significant linear correlation with tumor size $(R=0.39, P<0.02)$.

Conclusion: The performance of ADC value as a newly proposed prognostic parameter follows with the degree of tumor differentiation and that may recognize extremely aggressive RCC. RCC with low ADC values should be inspected extensively for the risk of high pathological grade, high clinical stage, and distant metastasis.
\end{abstract}

\section{Background}

Renal cell carcinoma (RCC) is a blended gathering of tumors that vary histologically with extensively differing prognosis [1]. It represents $2-3 \%$ of every single grownup malignant growth and is the sixth reason for death by tumor all through the world. Over $80 \%$ of renal tumors that emerge in the renal parenchyma are RCC, while most of renal pelvis malignancies are transitional cell carcinomas (TCCs) [2]. The three most basic subtypes of RCC are (i) clear-cell carcinoma, a standout among the most widely recognized sorts, representing $70-80 \%$ of cases; (ii) papillary renal cell carcinoma, representing about $10-15 \%$ of cases; and (iii) chromophobe renal carcinoma, which is the least normal, representing $5 \%$ of all RCCs [3].

Prognostic factor is an element that can be utilized to evaluate the risk of disease recurrence, metastatic spread,

\footnotetext{
* Correspondence: mandw20022002@hotmail.com

${ }^{+}$Mohammad Sabr and Eman Roshy contributed equally to this work.

${ }^{1}$ Department of Radiology, Sohag University Hospital, Sohag, Egypt

Full list of author information is available at the end of the article
}

and the clinical outcome. Guarantee of prognostic elements is fundamental for the management of RCC [4].

Prognostic elements can be anatomical (tumor size and stage), histological (histological type and grade), clinical (performance status, local symptoms, and cachexia), and molecular factors [5].

All of these features are not impeccably unique when handled alone. In this manner, an expanding number of prognostic systems or nomograms combining the independent prognostic factors have been developed. They were found to be more accurate using each factor alone [1].

Diffusion-weighted imaging (DWI) may be justifiably different from computed tomography (CT) to outline renal masses, especially in patients with renal insufficiency. DWI was able to differentiate benign lesions from RCCs and allowed a non-contrast alternative for excluding malignancy [6].

A few reports recommend that ADC might be related well with morphologic and histologic prognostic parameters in RCC [7]. Thus, the minimum ADC was observed to be an independent factor for recurrence of RCC after nephrectomy [8]. Yoshida et al. exhibited a 
measurably noteworthy distinction in the ADC between T1a RCC (estimate $\leq 4 \mathrm{~cm}$ ) with or without lymph nodes or metastasis [9]. Therefore, we hypothesize that the $\mathrm{ADC}$ value may be one of the prognostic factors for tumor aggressiveness in patients with RCC. Therefore, we planned to estimate the ADC value as a prognostic factor for patients with RCC, as well as the correlation between the $\mathrm{ADC}$ value and other known prognostic parameters, including histopathological grade and clinical staging.

\section{Methods}

\section{Patients}

This retrospective research was approved by our institutional medical review board. Patient data were secured through coded files to ensure privacy and confidentiality. The study was conducted between February 2016 and September 2018.

We retrospectively collected and analyzed the MRI examinations of 50 patients with a histopathological diagnosis of RCC.

All lesions were confirmed at histopathologic examination after partial or total nephrectomy.

RCC was further divided into clear-cell carcinoma $(n=28)$, papillary carcinoma $(n=12)$, chromophobe carcinoma $(n=6)$, and non-classified carcinoma $(n=4)$.

Histopathological diagnosis and Fuhrman nuclear grading of the RCC served as the standard references for the statistical analysis.

The clinical stage follows the TNM staging system of the American Joint Committee on Cancer. This included 29 pathologically proven low-stage (I and II) lesions and 21 high-stage (III and IV) RCCs.

Imaging diagnosis was used to determine the preclinical stage. Imaging with ultrasound and plain chest radiographs were routinely acquired. Preoperative computed tomography and MRI was preoperatively performed. Metastasis was evaluated by other investigations including brain and bone scan if indicated.

\section{MRI}

All patients were scanned using 1.5 Tesla (Achieva 1.5 tesla SE- Philips) equipped with body phased-array coil. Magnevist $(0.1 \mathrm{mmol} / \mathrm{kg})$ was injected i.v at a rate of 1 $\mathrm{ml} / \mathrm{s}$ followed by two-dimensional fast spoiled gradient contrast-enhanced sequences.

The protocol included respiratory-gated T2-weighted images and T2 fat-saturated sequence, pre- and post-contrast, breath-hold three-dimensional (3D) gradient fat-saturated T1-weighted sequence, breath-hold in- and out-of-phase sequence, and single-shot echo-planar diffusion-weighted sequence (DW) sequence using the following parameters: TR/TE: 8000/74-104 ms, slice thickness, $5 \mathrm{~mm}$, interslice gap, $0 \mathrm{~mm}$, FOV, 42-46, and matrix 128/128. $b$ value of $800 \mathrm{~s} / \mathrm{mm}^{2}$ was used to calculate the ADC value.

The ADC value was calculated by placing a region of interest (ROI) which was chosen to include solid components of the tumor and was set as large as possible. We quantified the ADC by physically applying a region of interest (ROI) to cover the solid parts of the tumor which was set in as broad an area as possible. Exceptional consideration was taken to maintain a strategic distance from necrotic, cystic, and hemorrhagic zones inside the tumors. In instances of tissues not showing diffusion restriction, the ROI was set in the most homogeneous part. These measurements were performed three times for each lesion and values were averaged to minimize measurement errors.

\section{MRI evaluation}

The MRI examination for all RCC was independently analyzed and then correlated with the pathology findings.

MRI images for renal masses were evaluated by one reviewer (MI) with 10 years of experience, who was blinded to the pathologic profile and clinical outcome and evaluated the images, including subtraction datasets.

The ADC was calculated by the software, where the signal intensity obtained at $b=800 \mathrm{~s} / \mathrm{mm}^{2}$.

The size of RCC lesions was calculated, and the greatest diameter was considered for statistical analysis.

All pathological data were analyzed using Fuhrman classification which assigns tumors with grades of IIV [10].

Tumor necrosis or cystic feature was defined as the area at the central location within the tumor, which shows high signal intensity on T2W images, low signal intensity on T1W images, and absence of enhancement.

The evaluation of a growth pattern was built on the largest axis of the tumor; cortical pattern was considered when RCC lesion was well defined without peripheral extension to the adjacent tissue whereas a tumor was classified as infiltrative if it had any degree of exophytic growth of tumor outside the expected contour of renal cortical parenchyma, as described previously $[11,12]$.

\section{Clinical stage}

Distant metastasis was determined by abdominal and pelvic ultrasound examination, plain $\mathrm{x}$-ray chest radiographs, and computed tomography. A radio-isotope scanning of the bone and brain or other investigation was only performed if indicated. A lymph node was considered positive if it had a maximum diameter larger than $1 \mathrm{~cm}$ with heterogeneity of enhancement or an irregular contour. Enlarged lymph nodes were not routinely and pathologically confirmed. 


\section{Statistical analysis}

We summarized the data as mean \pm standard deviation (continuous variables) or as percentages (categorical variables). Normal distribution of data was preliminarily verified by the Shapiro-Wilk test.

For statistical analysis, papillary carcinoma, chromophobe carcinoma, and non-classified carcinoma were considered as non-clear-cell carcinoma $(n=22)$, because of the small number of cases.

The relationship between ADC values and tumor size, tissue component (solid or mixed), unenhanced T1, growth pattern, histopathological diagnosis, histological grade, clinical stage, and distant metastasis were analyzed. Correlations between groups were assessed using Spearman's rank correlation analysis. Differences in the variables were evaluated by the Kruskal-Wallis test, Mann-Whitney's non-parametric test, or the $\chi^{2}$ test. Probability values of $P \leq 0.05$ were considered statistically significant. One way ANOVA analysis of variance was used to test the differences between more than two groups, followed by post hoc Tukey's test. If the test revealed a significant difference, receiver operating characteristic (ROC) analysis was performed to determine the area under the ROC curve and the optimal cutoff for the sensitivity, specificity, positive predictive value (PPV), negative predictive value (NPV), and accuracy of ADC values.

All statistical analyses were performed using SPSS $^{\circ}$ version 16.0 statistical software (SPSS Inc., Chicago, IL).

\section{Results}

\section{Patients}

Ultimately, 50 patients with 50 RCCs were included in the study. Of the 50 patients included in the study, 34 were females $(68 \%)$ and 16 were male (32\%) (see Table 1).

Histopathology revealed 28 (56 \%) clear-cell carcinomas and $22(44 \%)$ non-clear carcinoma (including 12 (24 \%) papillary renal cell carcinoma, 6 (12\%) chromophobe renal cell carcinoma, and 4 (8\%) unclassified carcinoma).

The histopathological grading was previewed as follows: 24 (48 \%) grade 1, 5 (10 \%) grade II, 16 (32\%) grade III, and $5(10 \%)$ grade IV lesions. The mean size of the RCC lesions was $6.1 \mathrm{~cm}$ (range $2-10 \mathrm{~cm}, \mathrm{SD} \pm 2.1$ $\mathrm{cm})$. Thirteen lesions $(26 \%)$ have size $\leq 4 \mathrm{~cm}$, while 37 lesions $(74 \%)$ have size $>4 \mathrm{~cm}$. Moreover, $26(52.8 \%)$ lesions exhibit infiltrative growth (see Figs. 1 and 2), and the presence of mixed tissue component (cystic/necrosis) was found in 16 (32\%) lesions (see Fig. 3).

Distant metastasis was found in 21(42\%) lesions. About $64.3 \%$ of clear RCC patients have lymph node metastasis. Approximately 34 (68 \%) lesions were solid while 16 (32\%) lesions were mixed.

All RCC had bright signal intensity on DW imaging, but, on unenhanced T1-weighted sequences, 33 RCC (66
Table 1 Features of prognostic factors of 50 RCC

\begin{tabular}{lll}
\hline Characteristic & & $\begin{array}{l}\text { Value (mean } \pm \\
\text { SD) }\end{array}$ \\
\hline Age (years), mean \pm SD & & $54.86 \pm 8.3$ \\
ADC* & & $1.5 \pm 0.2$ \\
Gender (no., \%) & Male & $16(32 \%)$ \\
& Female & $34(68 \%)$ \\
Tumor size (no., \%) & $\leq 4 \mathrm{~cm}$ & $13(26 \%)$ \\
& $>4 \mathrm{~cm}$ & $37(74 \%)$ \\
Tissue component (no., & Solid & $34(68 \%)$ \\
\%) & Mixed (cystic/necrotic) & $16(32 \%)$ \\
Unenhanced T1 & Hypointense & $33(66 \%)$ \\
& Isointense & $17(34 \%)$ \\
Tumor histology (no., \%) & Clear-cell carcinoma & $28(56 \%)$ \\
& Non-clear-cell & $22(44 \%)$ \\
& carcinoma & \\
Growth pattern (no., \%) & Infiltrative & $26(52 \%)$ \\
& Cortical & $24(48 \%)$ \\
Clinical stage & Low-stage (1 and II) & $29(58 \%)$ \\
& High-stage (III and IV) & $21(42 \%)$ \\
Lymph node metastasis & Yes & $21(42 \%)$ \\
& No & $29(58 \%)$ \\
Tumor grade (no., \%) & I & $24(48 \%)$ \\
& II & $5(10 \%)$ \\
& III & $16(32 \%)$ \\
& IV & $5 \%)$ \\
& &
\end{tabular}

$*\left(\right.$ mean $\left.\times 10^{-3} \mathrm{~mm}^{2} / \mathrm{s} \pm \mathrm{SD}\right)$

\%) were hypointense and 17 RCC (34\%) were isointense. The distribution of ADC values by histopathological subtype can be seen in Fig. 4.

\section{Clear-cell RCC versus non-clear RCC}

The comparison between the features of prognostic factors of clear and non-clear-cell RCC can be seen in Table 2 .

Among the various prognostic factors, growth pattern $(P=0.01)$, clinical stage $(P<0.05)$, distant metastasis $(P<0.05)$, and histological grade $(P=0.003)$ were significantly different.

Clear RCC had a mean ADC value of $1.6 \times 10^{-3} \mathrm{~mm}^{2} / \mathrm{s}$ (range $1.2-1.8 \times 10^{-3} \mathrm{~mm}^{2} / \mathrm{s}$, SD $0.2 \times 10^{-3} \mathrm{~mm}^{2} / \mathrm{s}$ ), which was higher than non-clear RCC $\left(1.5 \times 10^{-3} \mathrm{~mm}^{2} / \mathrm{s}\right)$. However, there was no evidence of statistically significant differences or correlation in between $(P=0.1$ and $r=$ $0.22, P=0.13$ ) (Table 3).

The performance of ADC for differentiating clear RCC from non-clear RCC is shown in Fig. 5. Selection of $1.4 \times 10^{-3} \mathrm{~mm}^{2} / \mathrm{s}$ as a cutoff point of ADC value revealed an area under curve (AUC) of 0.62 , sensitivity of $53.6 \%$, and specificity of $72.7 \%$.

\section{Relation between $A D C$ and prognostic factors}

The relations between mean ADC values and prognostic factors are shown in Table 3. The ADC values between groups were non-normally distributed. The mean of 

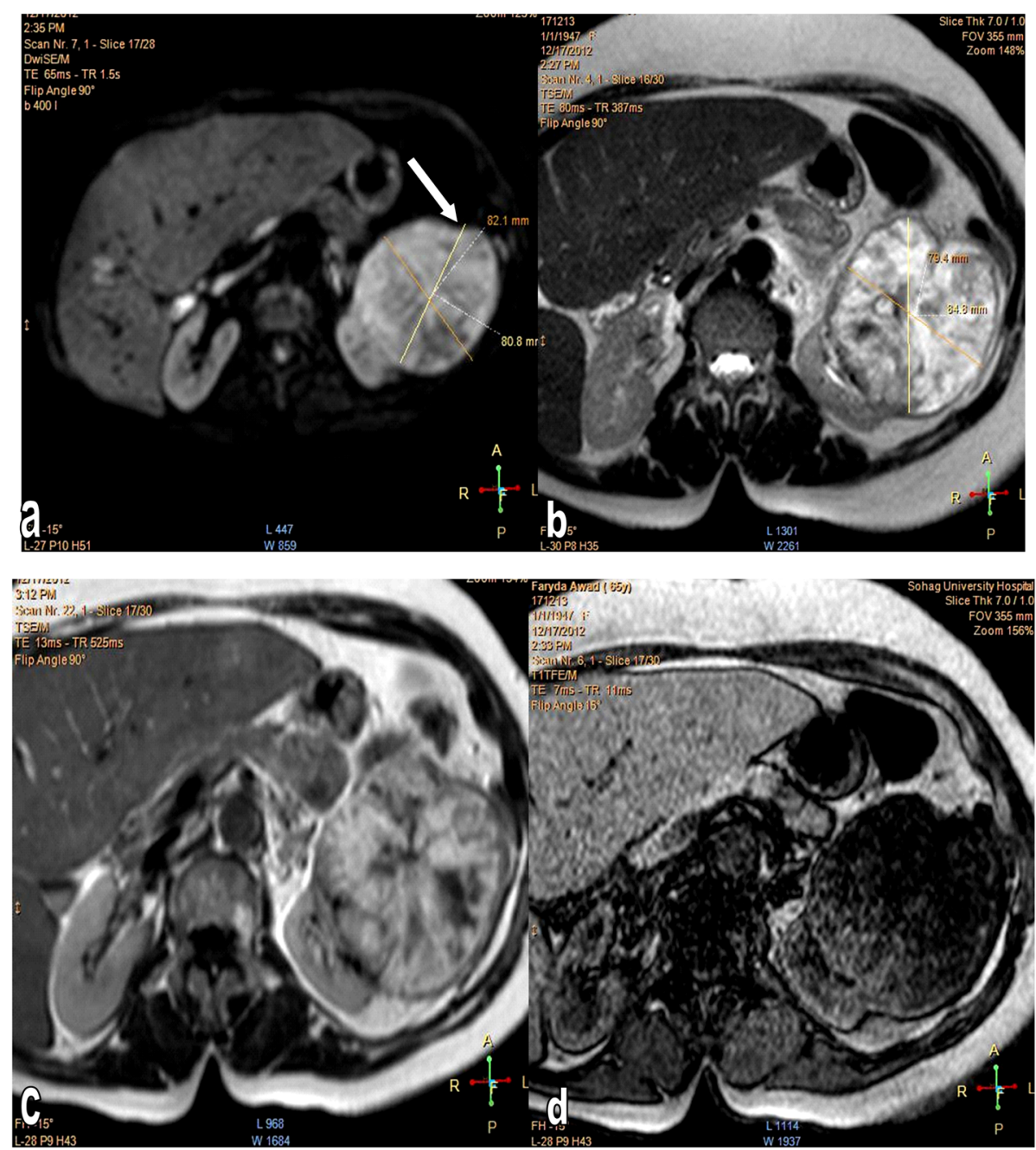

Fig. 1 65-year-old man with clear-cell renal cell carcinoma in left kidney. a Axial T1-weighted image shows the infiltrative tumor (arrow) as slightly hyperintense. $\mathbf{b}$ On T2-weighted MR image, the tumor (arrow) shows heterogeneous hyperintensity, as compared to the normal cortex. $\mathbf{c}$ Contrast-enhanced axial T1-weighted images show heterogeneous enhancement in the tumor (arrow) at corticomedullary phase and restricted diffusion on DWl; the ADC value was $1.6 \times 10^{-3} \mathrm{~mm}^{2} / \mathrm{s}(\mathbf{d})$

ADC values for all RCC was $1.5 \times 10^{-3} \mathrm{~mm}^{2} / \mathrm{s}$ (range $1.2-1.8 \times 10^{-3} \mathrm{~mm}^{2} / \mathrm{s}, \mathrm{SD} 0.2 \times 10^{-3} \mathrm{~mm}^{2} / \mathrm{s}$ ).

There was a statistically significant difference between the ADC values and prognostic factors including gender, tumor size, cystic/necrotic features, growth pattern, clinical stage, distant metastasis, histological grade, and unenhanced T1 (see Table 3).

Prognostic factors associated with low ADC values $(\leq$ $1.4 \times 10^{-3} \mathrm{~mm}^{2} / \mathrm{s}$ ) were male gender, tumor size $\leq 4 \mathrm{~cm}$, iso T1 signal intensity, solid lesions, infiltrative growth pattern, cystic/necrotic features, distant metastasis, grade IV, and high-stage (III and IV) RCCs Figs. (1, 3, and 2).

Prognostic factors with statistically significant positive correlation were gender $(r=0.28, P=0.05)$ and tumor size $(r=0.48, P<0.05)$.
Prognostic factors with statistically significant negative correlation were cystic/necrotic feature $(r=-0.4, P=$ $0.004)$, growth pattern $(r=-0.3, P=0.01)$, clinical stage $(r=-0.4, P=0.01)$, distant metastasis $(r=-0.4, P=0.01)$, histological grade $(r=-0.4, P=0.004)$, and unenhanced T1 $(r=-0.5, P=0.001)$.

The performance of ADC for differentiating low-stage from high-stage RCC is shown in Fig. 6. Selection of $1.2 \times$ $10^{-3} \mathrm{~mm}^{2} / \mathrm{s}$ as a cutoff point of ADC value revealed an AUC of 0.6 , sensitivity of $42.9 \%$, and specificity of $100 \%$.

\section{Discussion}

In the present study, estimation of ADC value of RCC was significantly correlated with gender, tumor size, 
Table 2 Features of prognostic factors of 28 clear and 22 non-clear RCC

\begin{tabular}{|c|c|c|c|c|}
\hline Parameter & & Clear RCC & Non-clear RCC & $P$ value \\
\hline Tumor size & $\begin{array}{l}\leq 4 \mathrm{~cm} \\
>4 \mathrm{~cm}\end{array}$ & $\begin{array}{l}10(35.7) \\
18(64.3)\end{array}$ & $\begin{array}{l}3(13.6) \\
19(86.4)\end{array}$ & 0.07 \\
\hline Sex & $\begin{array}{l}\text { Male } \\
\text { Female }\end{array}$ & $\begin{array}{l}8(28.6) \\
20(71.4)\end{array}$ & $\begin{array}{l}8(36.4) \\
14(63.6)\end{array}$ & 0.6 \\
\hline Age (years) & & $54.3 \pm 8.7$ & $55.6 \pm 7.9$ & 0.6 \\
\hline $\mathrm{ADC}^{*}$ & & $1.6 \pm 0.2$ & $1.5 \pm 0.2$ & 0.3 \\
\hline Unenhanced T1 & $\begin{array}{l}\text { Hypointense } \\
\text { Isointense }\end{array}$ & $\begin{array}{l}18(64.3) \\
10(35.7)\end{array}$ & $\begin{array}{l}15(68.2) \\
7(31.8)\end{array}$ & 0.8 \\
\hline Tissue component & $\begin{array}{l}\text { Solid } \\
\text { Mixed (cystic/necrotic) }\end{array}$ & $\begin{array}{l}18(64.3) \\
10(35.7)\end{array}$ & $\begin{array}{l}16(72.7) \\
6(27.3)\end{array}$ & 0.5 \\
\hline Growth pattern & $\begin{array}{l}\text { Infiltrative } \\
\text { Cortical }\end{array}$ & $\begin{array}{l}19(67.9) \\
9(32.1)\end{array}$ & $\begin{array}{l}7(31.8) \\
15(68.2)\end{array}$ & $0.01^{*}$ \\
\hline Clinical stage & $\begin{array}{l}\text { Low-stage ( } 1 \text { and II) } \\
\text { High-stage (III and IV) }\end{array}$ & $\begin{array}{l}10(35.7) \\
18(64.3)\end{array}$ & $\begin{array}{l}19(68.4) \\
3(13.6)\end{array}$ & $0.000^{*}$ \\
\hline Lymph node metastasis & $\begin{array}{l}\text { Yes } \\
\text { No }\end{array}$ & $\begin{array}{l}18(64.3) \\
10(35.7)\end{array}$ & $\begin{array}{l}3(13.6) \\
19(68.4)\end{array}$ & $0.000^{*}$ \\
\hline Tumor grade & $\begin{array}{l}\text { I } \\
\text { II } \\
\text { III } \\
\text { IV }\end{array}$ & $\begin{array}{l}9(32.1) \\
1(3.6) \\
13(46.4) \\
5(17.9)\end{array}$ & $\begin{array}{l}15(68.2) \\
4(18.2) \\
3(13.6) \\
0(0.0)\end{array}$ & $0.003^{*}$ \\
\hline
\end{tabular}

*(mean $\left.\times 10^{-3} \mathrm{~mm}^{2} / \mathrm{s} \pm \mathrm{SD}\right)$

cystic/necrotic features, growth pattern, clinical stage, distant metastasis, histological grade, and unenhanced T1. The prognostic factors of RCC accompanied by significantly low ADC values were male gender, size $\leq 4$ $\mathrm{cm}$, solid component, isointense on unenhanced $\mathrm{T} 1$, infiltrative growth, cystic/necrotic features, presence of distant metastasis, grade IV, and high-stage (III and IV) RCCs.

A $b$ value of $800 \mathrm{~s} / \mathrm{mm}^{2}$ was used in the current study because we had relatively few cases for histopathological

Table 3 Relation between mean ADC values and prognostic factors in 50 patients with 50 RCC

\begin{tabular}{|c|c|c|c|c|c|}
\hline \multirow[t]{2}{*}{ Prognostic factors } & & \multirow{2}{*}{$\begin{array}{l}\mathrm{ADC}(\times \\
10^{-3} \\
\mathrm{~mm}^{2} \\
\left.\mathrm{~s}^{-1}\right) \\
\text { (mean } \pm \\
\mathrm{SD})\end{array}$} & \multirow{2}{*}{$\begin{array}{l}\text { Univariate } \\
\text { analysis ( } P \\
\text { value) }\end{array}$} & \multicolumn{2}{|c|}{ Correlation coefficient } \\
\hline & & & & $r$ & $P$ value \\
\hline Tumor size & $\begin{array}{l}\leq 4 \mathrm{~cm} \\
>4 \mathrm{~cm}\end{array}$ & $\begin{array}{l}1.3 \pm 0.2 \\
1.6 \pm 0.2\end{array}$ & $0.001^{*}$ & 0.48 & $0.00^{*}$ \\
\hline Sex & $\begin{array}{l}\text { Male } \\
\text { Female }\end{array}$ & $\begin{array}{l}1.4 \pm 0.2 \\
1.6 \pm 0.2\end{array}$ & 0.05 & 0.28 & $0.05^{*}$ \\
\hline Tissue component & $\begin{array}{l}\text { Solid } \\
\text { Mixed (cystic/necrotic) }\end{array}$ & $\begin{array}{l}1.4 \pm 0.2 \\
1.6 \pm 0.1\end{array}$ & $0.005^{*}$ & -0.4 & $0.004^{*}$ \\
\hline Unenhanced T1 & $\begin{array}{l}\text { Hypointense } \\
\text { Isointense }\end{array}$ & $\begin{array}{l}1.6 \pm 0.2 \\
1.4 \pm 0.2\end{array}$ & $0.001^{*}$ & -0.46 & $0.001^{*}$ \\
\hline Histopathology & $\begin{array}{l}\text { Clear RCC } \\
\text { Non-clear RCC }\end{array}$ & $\begin{array}{l}1.5 \pm 0.2 \\
1.6 \pm 0.2\end{array}$ & 0.1 & 0.22 & 0.13 \\
\hline Growth pattern & $\begin{array}{l}\text { Infiltrative } \\
\text { Cortical }\end{array}$ & $\begin{array}{l}1.4 \pm 0.2 \\
1.6 \pm 0.2\end{array}$ & $0.02^{*}$ & -0.3 & $0.01^{*}$ \\
\hline Clinical stage & $\begin{array}{l}\text { Low-stage ( } 1 \text { and II) } \\
\text { High-stage (III and IV) }\end{array}$ & $\begin{array}{l}1.6 \pm 0.2 \\
1.4 \pm 0.2\end{array}$ & $0.01^{*}$ & -0.4 & $0.01^{*}$ \\
\hline Lymph node metastasis & $\begin{array}{l}\text { Yes } \\
\text { No }\end{array}$ & $\begin{array}{l}1.4 \pm 0.2 \\
1.6 \pm 0.2\end{array}$ & $0.01^{*}$ & -0.4 & $0.01^{*}$ \\
\hline Tumor grade & $\begin{array}{l}\text { I } \\
\text { II } \\
\text { III } \\
\text { IV }\end{array}$ & $\begin{array}{l}1.6 \pm 0.2 \\
1.6 \pm 0.1 \\
1.5 \pm 0.3 \\
1.3 \pm 0.1\end{array}$ & $0.03^{*}$ & -0.4 & $0.004^{*}$ \\
\hline
\end{tabular}



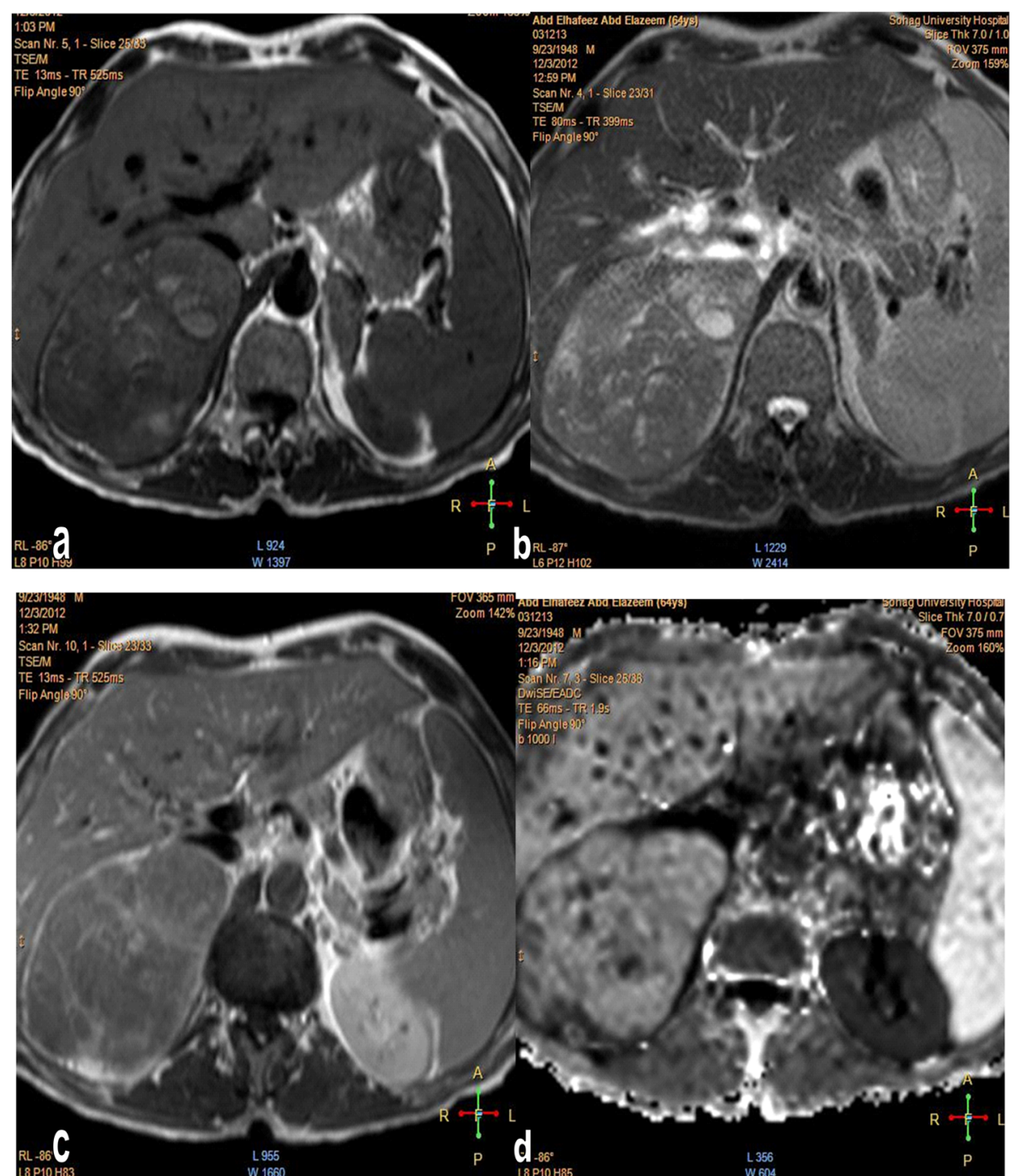

Fig. 2 a-d A 62-year-old woman with well-defined cortical clear-cell RCC measuring ( $30 \times 34 \mathrm{~mm}$ ). There is a small right renal lesion (circle) showing a low signal on the axial T1-weighted (T1WI) (a), high signal on the axial T2-weighted (b), and homogenous contrast enhancement on the postcontrast axial T1WI (c). Diffusion-weighted imaging with a $b$ value of 800 shows restricted diffusion of the lesion (d)

analysis and the study was retrospective in type. We did not encompass benign tumor lesions, which narrow the use of ADC values for discriminating malignant from benign tumors. With increasing $b$ values, improved qualitative images with a preferable signal to noise ratio are obtained [13].

In the current study, with a $b$ value of $800 \mathrm{~s} / \mathrm{mm}^{2}$, clear RCC had higher mean ADC values than non-clear RCC.

The previous results varied in their evaluation; although most of them had similar results, few disagreed. Similar results were with Youn et al., who showed high ADC $\left(1.6 \times 10^{-3} \mathrm{~mm}^{2} / \mathrm{s}\right)$ for clear RCC compared with ADC for non-clear RCC $\left(1.5 \times 10^{-3} \mathrm{~mm}^{2} / \mathrm{s}\right)$ [14]. Sharma et al. found ADC $\left(1.6 \times 10^{-3} \mathrm{~mm}^{2} / \mathrm{s}\right)$ with clear RCC and ADC $\left(1 \times 10^{-3} \mathrm{~mm}^{2} / \mathrm{s}\right)$ for non-clear RCC [15]. Cheng et al., in a study of 85 RCC, observed that non-clear RCC had significantly lower mean ADC values $\left(1.1 \times 10^{-3}\right.$ $\left.\mathrm{mm}^{2} / \mathrm{s}\right)$ than clear-cell RCC $\left(1.8 \times 10^{-3} \mathrm{~mm}^{2} / \mathrm{s}\right)[16]$. Kim et al. also reported that non-clear-cell RCC had significantly lower mean ADC values $\left(1.6 \times 10^{-3} \mathrm{~mm}^{2} / \mathrm{s}\right)$ than clear-cell RCC $\left(1.8 \times 10^{-3} \mathrm{~mm}^{2}\right)$ [17].

On another side, the results of Paudyal et al. proved that ADC value for clear RCC was lower $\left(1.61 \times 10^{-3} \mathrm{~mm}^{2} / \mathrm{s}\right)$ than in non-clear RCC $\left(6.72 \pm 1.85 \times 10^{-3} \mathrm{~mm}^{2} / \mathrm{s}\right)$ [18].

There is no doubt that evaluation of ADC value depends mainly on the number of cells and the relatively intercellular space which in turn can restrict water movement. Clear RCC tumors are characterized by narrow intercellular space due to presence of large cell and rich cytoplasm, in contrast to non-clear RCC. In the results of Paudyal, although different in appearance, the ADC values 


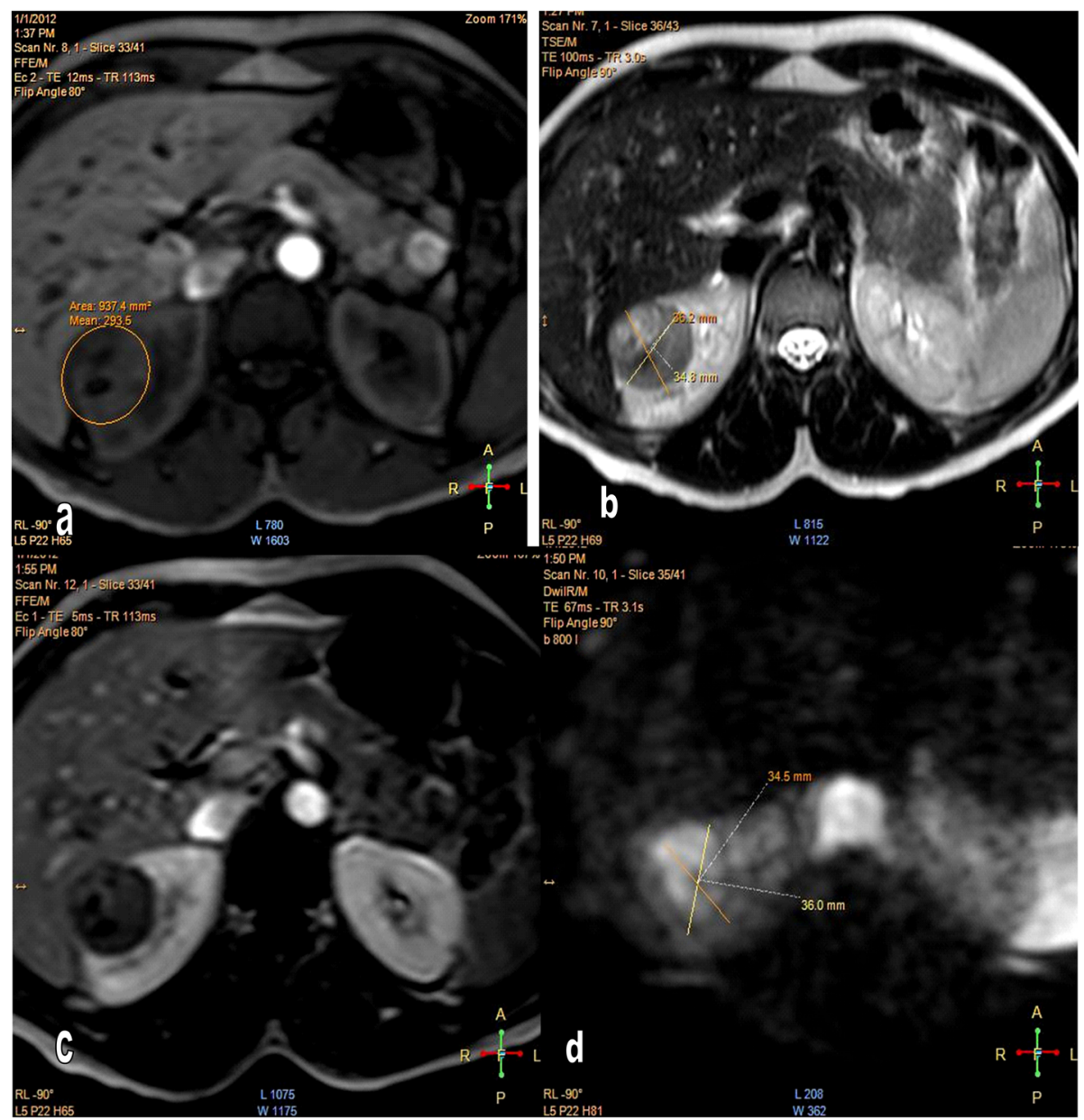

Fig. 3 Male patient, 64 years of age, evidence of large upper polar right kidney solid mass lesion with infiltrative growth (arrow), displaying low signal in T1 and high signal in T2 $(\mathbf{a}, \mathbf{b})$, showing moderate enhancement after IV contrast administration and restricted diffusion on DWl; the $A D C$ value was $1.2 \times 10^{-3} \mathrm{~mm}^{2} / \mathrm{s}(\mathbf{c}$, d), and papillary RCC was pathologically confirmed after radical nephrectomy

largely agreed, and this could be due to the size of samples taken and the nature of the tumors. So, further studies with larger patient populations are warranted [18].

The number of cells is a crucial indicator of tumor grade [19]. It has been suggested that the decreased ADC value may be due to their increased cellularity, larger nuclei with more abundant macromolecular proteins, and less extracellular space [20, 21].

The present study demonstrated a significant inverse relationship between ADC values and histological grade. Low-grade tumors had higher ADC values than highgrade tumors.

Several studies reported similar results. Youn et al. found that high-grade tumor had lower mean ADC values $(1.3 \times$ $\left.10^{-3} \mathrm{~mm}^{2} / \mathrm{s}\right)$ than lower grade tumors $\left(1.7 \times 10^{-3} \mathrm{~mm}^{2} / \mathrm{s}\right)$ [14]. Kim et al. also reported that high-grade clear-cell RCC $\left(1.7 \times 10^{-3} \mathrm{~mm}^{2} / \mathrm{s}\right)$ was observed to have significantly lower mean ADC values than low-grade clear-cell RCC $(2.0 \times$ $10^{-3} \mathrm{~mm}^{2} / \mathrm{s}$ ) [17].
On another side, in a study including 57 patients, Rosenkrantz et al. revealed a strong positive correlation of the ADC to grading [22]. Yu et al. reported that there were statistically significant differences in the ADC values of low- and high-grade RCCs [20]. Conversely, Sandrasegaran et al. observed no significant difference in ADC values related to tumor grading [23].

Heterogeneity of RCC may explain this contradictory data, because some tumor presents areas of different grades, which are often found within the same tumor. Therefore, Gurel et al. [24] suggested that conventional MRI in addition with ADC was superior to percutaneous biopsy and might improve tissue characterization.

In the current study, there was a statistically significant difference in ADC values between low and high-stage RCCs. RCC accompanied by significantly low ADC values $\leq 1.2 \times$ $10^{-3} \mathrm{~mm}^{2} / \mathrm{s}$ is related to the presence of distant metastasis.

Our result agreed with the previous study, which found a statistically significant difference in the ADC 

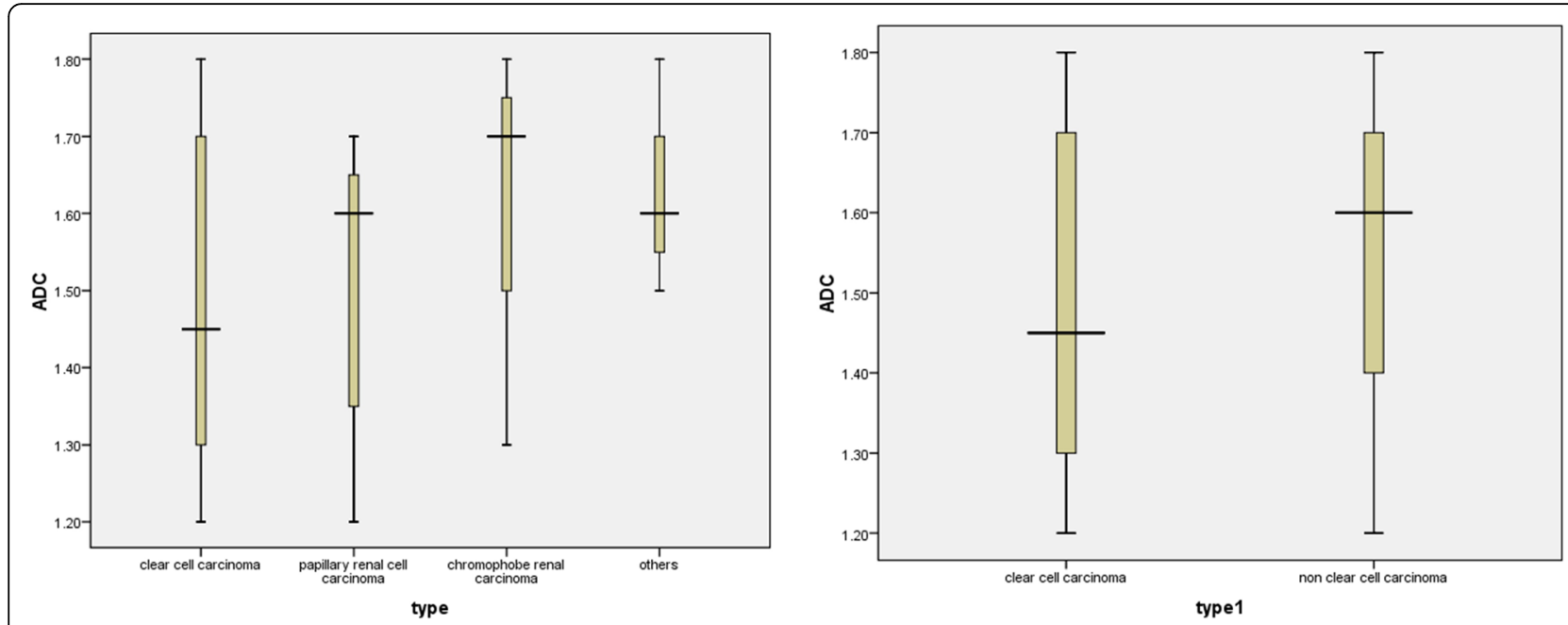

Fig. 4 Distribution of ADC values by histopathology group. Box plot showing ADC values (expressed as millimeter squared per second) for different histopathological types of RCC (figure on the right side is clear RCC versus papillary, chromophobe, and non-classified RCC, and figure on the left side is clear RCC versus non-clear RCC)

values between T1a clear-cell RCC and clear-cell RCC with distant metastasis [25].

In our study, there was statistically significant positive correlation between the size of RCC and ADC values. There are a limited number of studies focusing on the relation of the size of RCC and the ADC values. In a study of 49 patients, Mitsunari et al. showed a weak significant correlation between the tumor size and ADC value of clear-cell RCC [26].

In the general role, the size of RCC may not have a role in the determination of RCC aggressiveness but has a role in predicting the nuclear grade of RCC. So, ADC

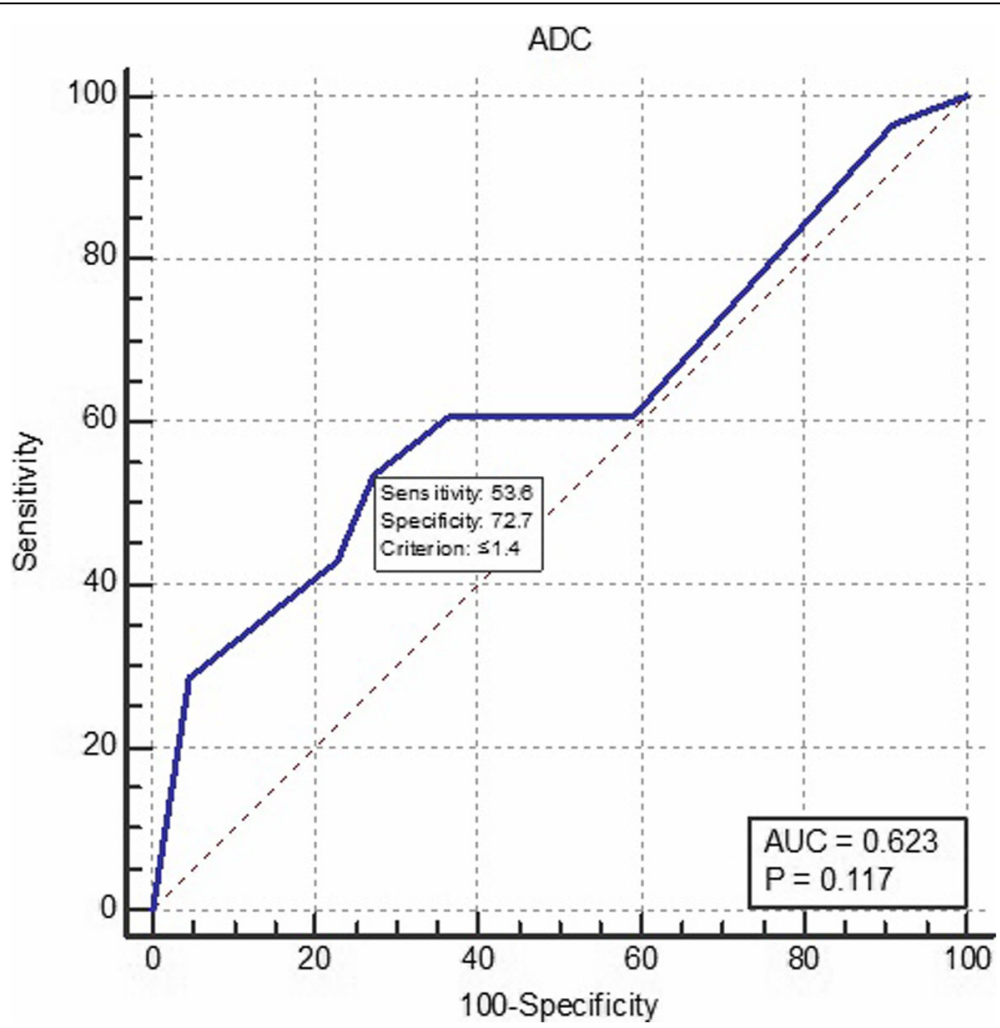

Fig. 5 ROC curve shows the performance of ADC for differentiating clear RCC from non-clear RCC (selection of $1.4 \times 10^{-3} \mathrm{~mm}^{2} / \mathrm{s}$ as a cutoff point of ADC value revealed an AUC of 0.62 , sensitivity of $53.6 \%$, and specificity of $72.7 \%$ ) 


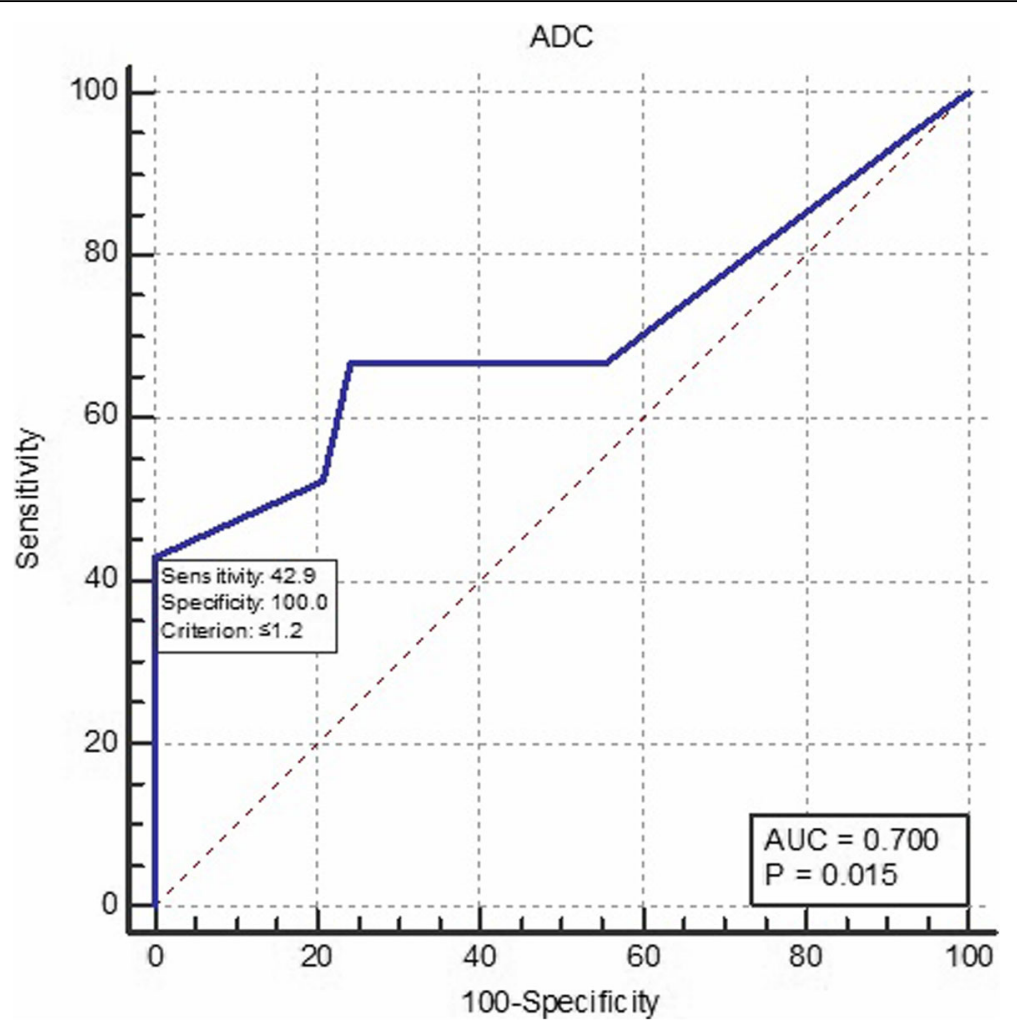

Fig. 6 ROC curve shows the performance of ADC for differentiating low-stage from high-stage RCC (selection of $1.2 \times 10^{-3} \mathrm{~mm}^{2} / \mathrm{s}$ as a cutoff point of ADC value revealed an AUC of 0.6 , sensitivity of $42.9 \%$, and specificity of $100 \%$ )

values should be used in conjunction with tumor size as an additional finding.

In the current study, RCC lesion with distant metastasis had statistically significant lower mean ADC values with strong negative correlation. A previous study reported that ADC values of clear RCC may be related to the presence of distant metastasis. Thus, in a clinical situation, clear-cell RCC with low ADC values should be inspected broadly for the risk of distant metastasis [26].

In our study, we have defined growth pattern as a parameter and analyzed its prognostic usefulness. The infiltrative lesion had low ADC value compared to cortical lesion, in addition to the strong positive correlation noted in between.

Recently, few reports considered that RCC with an infiltrative growth pattern may have more migration capacity than RCC with cortical growth pattern and adopted growth pattern as a parameters for RCC prognosis [27]. Further studies are crucial to approve the convenience of this parameter.

The presence of tumor necrosis is a well-established independent indicator of a poor prognosis for RCC, and presence of necrosis results in higher ADC values [18, 19]. In our study, there was a statistically significant positive correlation between the ADC values and tumor necrosis.
We found a strong negative correlation between ADC values and the tissue component. The solid lesions had statistically significantly lower mean ADC value levels than cystic/necrotic lesions.

The histology of RCC is heterogeneous and contains a lot of variety including necrosis, hemorrhage, debris, and solid tissues which elevate the value of ADC [1].

In our study, T1 isointense lesions were associated with lower ADC values, and there was a strong negative correlation between ADC values and T1 signal intensity. This result was seen in previously published data [28]. This compatibility might be a result of the homogeneity of the different lesions and the comparison between the same malignant group.

This study has several limitations. Firstly, the study had a retrospective, non-randomized design and single institutional series. Secondly, only one $b$ value $(800$ $\mathrm{mm}^{2} / \mathrm{s}$ ) was used for the estimation of the ADC. It may be fascinating to get additional $b$ values to obtain more strict ADC data. Thirdly, we did not estimate the reproducibility of the ADC values gathered for RCC.

\section{Conclusion}

In conclusion, evaluation of $A D C$ value of $R C C$ was significantly correlated with gender, tumor size, cystic/necrotic features, growth pattern, clinical stage, distant metastasis, 
histological grade, and unenhanced T1. RCC with low ADC values should be inspected extensively for the risk of high pathological grade, high clinical stage, and distant metastasis. The performance of ADC value as a newly proposed prognostic parameter follows with the degree of tumor differentiation and that may recognize extremely aggressive RCC.

\section{Abbreviations}

ADC: Apparent diffusion coefficient; CT: Computed tomography; DW: Diffusionweighted; DWI: Diffusion-weighted imaging; MRI: Magnetic resonance imaging; RCC: Renal cell carcinoma; TCCs: Transitional cell carcinomas

\section{Acknowledgements}

We would acknowledge Dr. M. Zaki, assistant professor in Sohag University, for his efforts in data collection.

\section{Authors' contributions}

$\mathrm{Ml}$ is the main author who contributed to the study design and analysis of patients' data and was responsible for the diagnostic procedure and writing of the publication. MS conceived of the study, participated in its design and coordination, and helped to draft the manuscript. ER participated in the design of the study and performed the statistical analysis. All authors read and approved the final manuscript.

\section{Funding}

Not applicable.

\section{Availability of data and materials}

The datasets used and/or analyzed during the current study are available from the corresponding author on reasonable request.

\section{Ethics approval and consent to participate}

Research committee approval has been granted for this study by the Medical Ethics Committee, Faculty of Medicine, Sohag University. Informed consent according to the criteria set by the local research ethics committee in our hospital had to be obtained in writing before research.

\section{Consent for publication}

All patients included in this research gave written informed consent to publish the data contained within this study. If the patient was less than 16 years old, deceased, or unconscious when consent for publication was requested, written informed consent for the publication of this data was given by their parent or legal guardian.

\section{Competing interests}

The authors declare that they have no competing interests.

\section{Author details}

'Department of Radiology, Sohag University Hospital, Sohag, Egypt. ${ }^{2}$ Urology Department, Sohag University Hospital, Sohag, Egypt. ${ }^{3}$ Department of Public Health and Community Medicine, Sohag University Hospital, Sohag, Egypt.

Received: 30 June 2019 Accepted: 30 August 2019

Published online: 12 September 2019

\section{References}

1. Volpe A, Patard JJ (2010) Prognostic factors in renal cell carcinoma. World J Urol 28:319-327

2. Low G, Huang G, Fu W, Moloo Z, Girgis S (2016 May 28) Review of renal cell carcinoma and its common subtypes in radiology. World J Radiol 8(5):484-500

3. Razek AA, Farouk A, Mousa A, Nabil N (2011 May-Jun) Role of diffusionweighted magnetic resonance imaging in characterization of renal tumors. J Comput Assist Tomogr. 35(3):332-336

4. ARNAUD MÉJEAN, STÉPHANE OUDARD, NICOLAS THIOUNN. Prognostic factors of renal cell carcinoma. The Journal of Urology, March 2003Volume 169, Issue 3, Pages 821-827.

5. Flanigan RC, Polcari AJ, Hugen CM (2011) Prognostic variables and nomograms for renal cell carcinoma. International Journal of Urology 18:20-31
6. Mytsyk Y, Borys Y, Komnatska I, Dutka I, Shatynska-Mytsyk I (2014 Sep 1) Value of the diffusion-weighted MRI in the differential diagnostics of malignant and benign kidney neoplasms - our clinical experience. Pol J Radiol 79:290-295

7. Hötker AM, Mazaheri Y, Wibmer A (2016 Jan) Use of DWI in the differentiation of renal cortical tumors. AJR. 206(1):100-105

8. Nishie A, Kakihara D, Asayama Y, Ishigami K, Ushijima Y, Takayama Y (2016) Apparent diffusion coefficient: an associative factor for recurrence after nephrectomy in localized renal cell carcinoma. J Magn Reson Imaging 43:166-172

9. Yoshida R, Yoshizako T, Hisatoshi A, Mori H, Tamaki Y, Ishikawa N (2017) The additional utility of apparent diffusion coefficient values of clear-cell renal cell carcinoma for predicting metastasis during clinical staging. Acta Radiol Open. 6:2058460116687174

10. Fuhrman SA, Lasky LC, Limas C (1982) Prognostic significance of morphologic parameters in renal cell carcinoma. Am J Surg Pathol 6:655-663

11. Verma SK, Mitchell DG, Yang R et al (2010) Exophytic renal masses: angular interface with renal parenchyma for distinguishing benign from malignant lesions at MR imaging. Radiology 255:501-507

12. Takahashi N, Leng S, Kitajima K, Gomez-Cardona D, Thapa P (2015 Dec) Small $(<4 \mathrm{~cm})$ Renal masses: differentiation of angiomyolipoma without visible fat from renal cell carcinoma using unenhanced and contrastenhanced CT. AJR Am J Roentgenol. 205(6):1194-1202

13. Borrelli P, Palma G, Tedeschi E (2015) Improving signal-to-noise ratio in susceptibility weighted imaging: a novel multicomponent non-local approach. PLoS One. 10(6):e0126835

14. Choi YA, Park CKKSY (2014) Subtype differentiation of renal cell carcinoma using diffusionweighted and blood oxygenation level-dependent MRI. AJR 203:W78-W84

15. Sharma R, Goyal A, Bhalla AS (2012) Diffusion-weighted MRI in renal cell carcinoma: a surrogate marker for predicting nuclear grade and histological subtype. Acta Radiol 53:349-358

16. Cheng L, Wang H, Zhang X (2010) Renal cell carcinoma: diffusion-weighted MR imaging for subtype differentiation at 3.0 T. Radiology 257:135-143

17. Kim CK, Choi YA, Park SY (2014) Subtype differentiation of renal cell carcinoma using diffusion-weighted and blood oxygenation leveldependent MRI. AJR Am J Roentgenol 203:W78-W84

18. Paudyal B, Paudyal P, Tsushima Y (2010 Apr) The role of the ADC value in the characterization of renal carcinoma by diffusion-weighted MRI. $\mathrm{Br} J$ Radiol. 83(988):336-343

19. Ito K, Seguchi K, Shimazaki H (2015 Jan) Tumor necrosis is a strong predictor for recurrence in patients with pathological T1a renal cell carcinoma. Oncol Lett. 9(1):125-130

20. Yu X, Lin M, Ouyang H (2012) Application of ADC measurement in characterization of renal cell carcinomas with different pathological types and grades by 3.0 T diffusion-weighted MRI. Eur J Radiol. 81:3061

21. Surov A, Meyer HJ, Wienke A (2017 May 10) Correlation between apparent diffusion coefficient (ADC) and cellularity is different in several tumors: a meta-analysis. Oncotarget. 8(35):59492-59499

22. Rosenkrantz AB, Niver BE, Fitzgerald EF, Babb JS, Chandarana H, Melamed J (2010) Utility of the apparent diffusion coefficient for distinguishing clear cell renal cell carcinoma of low and high nuclear grade. AJR 195

23. Sandrasegaran K, Sundaram CP, Ramaswamy R (2010) Usefulness of diffusion-weighted imaging in the evaluation of renal masses. AJR Am J Roentgenol. 194:438-445

24. Gurel S, Narra V, Elsayes KM (2013) Subtypes of renal cell carcinoma: MRI and pathological features. Diagn Interv Radiol 19:304-311

25. Yoshida R, Yoshizako T, Hisatosh A (2017 Jan) The additional utility of apparent diffusion coefficient values of clear-cell renal cell carcinoma for predicting metastasis during clinical staging. Acta Radiol Open 6(1)

26. Maruyama M, Yoshizako T (2015) Comparison of utility of tumor size and apparent diffusion coefficient for differentiation of low- and high-grade clear-cell renal cell. Acta Radiologica. 56(2)

27. Fukatsu A, Tsuzuki T, Sassa N (2013) Growth pattern, an important pathologic prognostic parameter for clear cell renal cell carcinoma. Am J Clin Pathol 140:500-505

28. Zhang J, Tehrani YM, Wang L, Ishill NM, Schwartz LH, Hricak H (2008) Renal. masses: characterization with diffusion-weighted MR imaging - a preliminary experience. Radiology 247:458-464

\section{Publisher's Note}

Springer Nature remains neutral with regard to jurisdictional claims in published maps and institutional affiliations. 